\title{
EVALUASI PEMBELAJARAN MATA KULIAH MENEJEMEN USAHA BUSANA MODISTE
}

\author{
Esin Sintawati $^{1}$, Rudi Nurdiansyah ${ }^{2}$, Nur Endah Purwaningsih ${ }^{3}$ \\ ${ }^{1,3}$ Program Studi Pendidikan Tata Busana \\ ${ }^{2}$ Program Studi Tata Busana \\ 1,2,3Universitas Negeri Malang \\ esin.sintawati.ft@um.ac.id
}

\begin{abstract}
ABSTRAK
Menejemen Usaha Busana (MUB) Modiste merupakan mata kuliah yang diselenggarakan Program Studi Tata Busana D3 maupun S1.Tujuan penelitian untuk (1) mengetahui pelaksanaan model pembelajaran pada MUB Modiste berkaitan dengan komponen konteks, (2) mengetahui efektivitas model pembelajaran Teaching Factory- enam Model pada tahap input yang berhubungan dengan teknis pengelolaan, administrasi, alokasi waktu serta sarana dan prasarana. Penelitian ini merupakan penelitian evaluasi yang bertujuan untuk mengetahui tingkatketerlaksanaan suatu kebijakan secaracermat dengan cara mengetahui efektivitasmasing-masing komponen yang dievaluasidengan pendekatan model CIPP (Context, Input, Process, Product). Hasil penelitian menunjukkan bahwa (1) pembelajaran MUB Modiste terlaksana karena telah memiliki landasan yuridis berupa kurikulum, sesuai dengan visi misi program studi, (2) pembelajaran MUB Modiste didukung oleh aspek teknis pelaksanaan yang rinci dan konsisten, alokasi waktu pelaksanaan yang memadai untuk pelaksanaan pembelajaran usaha, administrasi yang standar sesuai yang berlaku serta sarana prasarana yang memadai, (3) aspek proses pelaksanaan pembelajaran MUB Modiste telah didukung oleh kompetensi dosen yang sesuai dan memadai, serta dalam prosesnya memiliki model yang sesuai dengan standar dan tujuan pembelajaran.
\end{abstract}

Kata Kunci: evaluasi pembelajaran, manajemen usaha modiste

\section{PENDAHULUAN}

Manajemen usaha busana (MUB) Modiste diselenggarakan pada program studi Tata Busana D3 maupun S1 sesuai dengan misi prodi dalam menyelenggarakan pendidikan dan pembelajaran yang berkualitas di bidang pendidikan teknologi dan vokasional busana untuk menghasilkan lulusan yang cerdas dan kompetitif. Standar kompetensi pada mata kuliah MUB modiste adalah: (1) agar mahasiswa memahami prinsip-prinsip pengelolaan usaha modiste/tailor, (2) dapat merencanakan usaha dibidang busana modiste/tailor, dan (3) menyelenggarakan kegiatan usaha modiste/tailor sesuai dengan prinsip-prinsip manajemen usaha bidang busana.

Model Pembelajaran pada MUB Modiste terdiri dari: (1) menerima pemberi order, (2) menganalisis order, (3) menyatakan kesiapan mengerjakan order, 4) mengerjakan order, 5) melakukan Quality Control, dan 6) menyerahkan order. Model pembelajaran ini merupakan model pembelajaran terpadu. Dosen berperan sebagai quality control dan konsultan, sedangkan mahasiswa berperan sebagai pengelola usaha merangkap tenaga kerja layaknya di industri. Model Pembelajaran ini memberi kesempatan kepada mahasiswa untuk berlatih dalam mengembangkan kompetensi personal, sosial, dan kompetensi akademik, yang diharapkan dapat mengoptimalkan pengembangan kompetensi lulusan.

Pelaksanaan Model Pembelajaran Modiste pada pembelajaran MUB modiste diharapkan mahasiswa mempunyai minat untuk berwirausaha. "Seseorang yang berminat untuk berwirausaha harus dapat menerima semua proses yang terjadi dalam wirausaha” 
(Purnama, 2009: 39). Mahasiswa harus mampu mempersiapkan bekal berupa sikap mental dan belajar untuk menguasai beberapa keterampilan yang menunjang dalam melaksanaan wirausaha.

Kajian secara kritis dan sistematis perlu dilakukan untuk melihat sejauh mana efektivitas model pembelajaran MUB modiste pada Prodi Tata Busana Jurusan TI FT UM. Penelusuran mendalam terhadap pelaksanaan model pelaksanaan MUB penting dilakukan, untuk melihat keefektifan model, peran serta mitra/konsumen dan aktivitas mahasiswa dalam melaksanakan MUB modiste. "Evaluasi terhadap sebuah program perlu dilakukan secara berkesinambungan terhadap latar belakang, masukan, proses, dan produk dengan menggunakan standar baku yang digunakan dalam menilai program yang sistemik” [11].Kenyataan tersebut mendorong peneliti melakukan evaluasi terhadap efektifitas model pembelajaran pada pelaksanaan MUB Modiste di Prodi Tata Busana Jurusan TI FT UM, mengingat: (1) Penerapan model pembelajaran MUB berbeda dengan model pembelajaran pada mata kuliah lain di prodi Tata Busana, dan belum pernah ada penelitian khusus untuk mengevaluasi efektivitasnya; dan (2) peneliti memandang perlu memberikan masukan agar pelaksanaan MUB pada Prodi Tata Busana khususnya, dan Jurusan TI FTUM pada umumnya dapat berjalan dengan efektif, dan (3) pemetaan masukan, proses, kelebihan serta kelemahan serta hasilnya dari dalam penerapan model pembelajaran MUB modiste sangat penting dilakukan untuk melihat sejauh mana efektivitasnya.

Evaluasi model pembelajaran sangatlah diperlukan, dengan memperhatikan segala bentuk usaha maupun sumber daya yang telah dikerahkan program studi dalam membangun model pembelajaran tersebut. Pengambilan keputusan yang sesuai dan tepat, strategiyang cermat, serta pendayagunaan model pembelajaran yang terencana dengan baik, akan mampu menghasilkan pendidikan yang unggul dalam menghadapi era globalisasi dan masa yang akan datang.
Penelitian ini berujuan untuk: (1) Mengetahui pelaksanaan model pembelajaran pada MUB Modiste berkaitan dengan komponen konteks, (2) Mengetahui efektivitas model pembelajaran TF-6M pada tahapan input yang berhubungan dengan teknis pengelolaan, administrasi, alokasi waktu serta sarana dan prasarana.

Penelitian ini penting untuk dilakukan mengingat: (1) Penerapan model pembelajaran MUB berbeda dengan model pembelajaran pada mata kuliah lain di prodi Tata Busana, dan belum pernah ada penelitian khusus untuk mengevaluasi efektivitasnya; (2) perlu masukan agar pelaksanaan MUB pada Prodi Tata Busana khususnya dapat berjalan dengan efektif, (3) pemetaan masukan, proses, kelebihan serta kelemahan serta hasilnya dari dalam penerapan model pembelajaran MUB modiste sangat penting dilakukan untuk melihat sejauh mana efektivitasnya, dan (4) memungkinkan adanya perubahan model pembelajaran yang lebih tepat selain selain yang sekarang diterapkan pada pembelajaran MUB modiste khususnya serta MUB lainnya.

\section{METODE}

Metode penelitian yang digunakan dalam evaluasi program pelaksanaanModel Pembelajaran pada mata kuliah MUB Modiste Prodi Tata Busana FT UM adalah metode penelitian evaluatif, yaitu upaya untuk mengetahui tingkat keterlaksanaan suatu kebijakan secara cermat dengan cara mengetahui efektivitas masing-masing komponen yang dievaluasi dengan pendekatan model CIPP (Context, Input, Process, Product).

Aspek konteks terkait dengan rekaman kondisi obyektif saat ini. Aspek input terkait dengan rekaman rencana program. Aspek proses berkaitan dengan rekaman penerapan program, sedangkan aspek produk terkait dengan rekaman pencapaian program. Setelah MUB modiste bertahun-tahun dijalankan, maka muncul pertanyaan apakah model pembelajarannya sudah efektif atau belum, maka dari itu perlu dilakukan evaluasi secara 
menyeluruh terhadap 4 aspek di atas. Sesuai objek penelitian, lokasi penelitian ini adalah Prodi Tata Busana Jurusan TI FT UM. Penelitian dilakukan tidak terbatas di lingkungan kampus, mengingat terdapat beberapa data yang diperlukan berada di luar kampus, yakni konsumen pemberi order kepada mahasiswa dalam melaksanakan MUB Modiste. Dalam rangka mendapatkan indikator data yang diperlukan dalam penelitian evaluasi program model CIPP, maka teknik pengumpulan data yang digunakan adalah observasi, angket dan analisis dokumen. Dalam penelitian evaluasi menggunakan model CIPP, dirumuskan aspek dan indikator yang dikelompokkan sesuai dengan komponen konteks, input, proses, dan produk yang bertujuan untuk mempermudah pelaksanaan evaluasi. Teknik pengumpulan dan analisis data seperti terlihat pada Tabel 1.

Tabel 1: Teknik Pengumpulan dan Analisis Data

\begin{tabular}{|c|c|c|c|c|}
\hline $\begin{array}{l}\text { Tahapan } \\
\text { Evaluasi }\end{array}$ & Aspek yang dievaluasi & Sumber Data & $\begin{array}{c}\text { Teknik Pengumpulan } \\
\text { Data }\end{array}$ & Analisis Data \\
\hline Konteks & $\begin{array}{l}\text { Landasanyuridis } \\
\text { Kelayakan prodi }\end{array}$ & $\begin{array}{l}\text { 1. Arsip Prodi } \\
\text { 2. Arsip Prodi }\end{array}$ & $\begin{array}{l}\text { 1. Analisis } \\
\text { 2. Dokumen } \\
\text { 3. Observasi }\end{array}$ & Legalitas \\
\hline Masukan & $\begin{array}{l}\text { Teknis Pengelolaan } \\
\text { Administrasi } \\
\text { Alokasi waktu } \\
\text { Sarana dan prasarana }\end{array}$ & $\begin{array}{l}\text { 1. Arsip Prodi } \\
\text { 2. Arsip Prodi } \\
\text { 3. Arsip Prodi } \\
\text { 4. Arsip Prodi }\end{array}$ & $\begin{array}{l}\text { 1. Analisis Dokumen } \\
\text { 2. Analisis Dokumen } \\
\text { 3. Analisis Dokumen } \\
\text { 4. Observasi }\end{array}$ & $\begin{array}{l}\text { 1. Deskriptif } \\
\text { 2. Deskriptif } \\
\text { 3. Deskriptif } \\
\text { 4. Deskriptif }\end{array}$ \\
\hline Proses & $\begin{array}{l}\text { 1. Kompetensi dosen } \\
\text { ProsesPembelajaran }\end{array}$ & $\begin{array}{l}\text { 1. Dosen } \\
\text { 2. Dosen, dan mahasiswa }\end{array}$ & $\begin{array}{l}\text { 1. Angket } \\
\text { 2. Observasi }\end{array}$ & $\begin{array}{l}\text { 1. Deskriptif } \\
\text { 2. Deskriptif }\end{array}$ \\
\hline Produk & $\begin{array}{l}\text { Hasil belajar } \\
\text { Tingkat Pencapaian } \\
\text { Perkembangan mahasiswa }\end{array}$ & $\begin{array}{l}\text { Arsip prodi dan } \\
\text { mahasiswa } \\
\text { f. Mahasiswa } \\
\text {. Konsumen }\end{array}$ & $\begin{array}{l}\text { 1. Analisis Dokumen } \\
\text { 2. Angket }\end{array}$ & $\begin{array}{l}\text { 1. Deskriptif } \\
\text { 2. Deskriptif }\end{array}$ \\
\hline
\end{tabular}

\section{HASIL DAN PEMBAHASAN}

Data yang dipaparkan meliputi data kontex atau latar belakang program MUB modiste, input atau masukan berupa teknis, alokasi waktu, administrasidata pelaksanaan program MUB Modiste, data efektivitas pelaksanaan MUB modiste, dan data Faktorfaktor yang menjadi kendala dalam pelaksanaan MUB modiste mahasiswa Prodi Tata Busana Jurusan TI FT UM.

\section{Konteks Pembelajaran MUB Modiste}

Landasan yuridis yang menjadi latar belakangnya diterapkan model pembelajaran MUB Modiste adalah dokumen kurikulum program studi Tata Busana, yang memuat tentang Visi dan Misi Program Studi, tujuan, profil lulusan, capaian pembelajaran, struktur mata kuliah, Sebaran mata kuliah setiap semester, serta deskripsi mata kuliah (Kurikulum Prodi Tata Busana 2017: 75).

Visi Prodi tata Busana adalah untuk mewujudkan Program Studi S1 Pendidikan Tata Busana yang unggul dan menjadi rujukan dalam penyelenggaraan pendidikan teknologi dan vokasional bidang Pendidikan Tata Busana. Sedangkan Misi yang berkaitan dengan pembelajaran MUB Modiste ada pada misi program studi antara lain: Menyelenggarakan pendidikan dan pembelajaran yang berkualitas di bidang pendidikan teknologi dan vokasional bidang busana untuk menghasilkan lulusan yang cerdas dan kompetitif.

Profil lulusan program studi tata busana yang melandasi adalah: (1) Calon Pendidik pada jalurpendidikan formal (Calon Guru SMK 
Pariwisata Bidang Keahlian Tata Busana); (2) Pendidik pada jalur pendidikan nonformal (instruktur pada lembaga kursus dan pelatihan bidang busana, mencakup pelatihan membuat hiasan kain dan busana, pelatihan menjahit, pelatihan membuat desain busana); (3) Perancang program pendidikan dan pelatihan di bidang busana; (4) Asisten Peneliti Bidang Pendidikan tata Busana; (5) Pengelola Butik/ Modiste/ Garmen; dan (6) Pengelola event pergelaran busana.

Mengacu pada visi, misi, tujuan, dan profil lulusan, maka matakuliah MUB Modiste dirumuskan menjadi mata kuliah keahlian bidang studi dengan bobot 3 sks 6js dengan Capaian Pembelajaran (learning outcome) sebagai berikut: Memahami prinsip-prinsip pengelolaan usaha modiste/tailor, mampu merencanakan usaha dibidang busana modiste/tailor, dan mampu menyelenggarakan kegiatan usaha modiste/tailor sesuai dengan prinsip-prinsip manajemen usaha bidang busana. Deskripsi Kompetensi meliputi: (1) Merancang usaha busana modiste/tailor,(2) Melalukan pengelolaan usaha modiste/tailor,( 3) Mengevaluasi pelaksanaan usaha, dan (4) Melaporkan kegiatan usaha (Kurikulum Tata Busana 2017: 112-113).

Berlandaskan pada aspek yuridis tersebut, maka MUB Modiste merupakan mata kuliah yang mengaplikasikan beberapa ilmu yang telah mendasari sebelumnya seperti manajemen usaha busana, perencanaan modiste, kewirausahaan, serta beberapa mata kuliah keahlian berkarya yakni berbagai mata kuliah teknik pembuatan busana.

Selain pada katalog dan kurikulum program studi, pengembangan kewirausahaan mahasiswa dan teaching factory terdapat pada dokumen rencana strategis Bisnis (Renstrabis) jurusan maupun program studi (2015: 34), antara lain: (1) Kurikulum program studi di Jurusan Teknologi Industri mencetak profil lulusan yang sesuai dengan kebutuhan di lembaga pendidikan maupun di industri; (2) Kurikulum program studi mempunyai persentase praktikum yang relatif besar dalam rangka menyiapkan lulusan yang mampu menyelenggarakan pembelajaran produktif; (3) Jurusan memiliki tenaga pengajar baik dari bidang kependidikan maupun non kependidikan; dan (4) Tersedia unit usaha yang merupakan bagian dari mata kuliah (MUB Catering, MUB café, MUB Restoran, MUB Modiste, MUB Butik, dan MUB Industri).

Penyelenggaraan model pembelajaran MUB Modiste ditinjau berdasarkan kelayakan program studi dapat dikatakan sangat layak. Program studi sudah terakreditasi BANPT, dan memiliki fasilitas belajar untuk penyelenggaraan MUB Modiste, yakni sudah dimilikinya laboratorium MUB Neckin dengan peralatan yang memadai bagi mahasiswa dalam menyelenggarakan pengelolaan usaha.

Sebelum mahasiswa menempuh mata kuliah MUB Modiste, Program studi tata busana sudah menyajikan beberapa mata kuliah pendukung yang membekali mahasiswa dalam kemampuan manajemen seperti manajemen usaha busana secara tiori, perencanaan modiste, dan kewirausahaan, serta pengalaman praktek di lapangan melalui praktik industri bagi mahasiswa, disamping mata kuliah keterampilan khusus yang membekali keterampilan mahasiswa dalam pembuatan berbagai jenis busana. Sejalan dengan itu, [15] bahwa bagi setiap orang yang akan menekuni usaha bidang busana pada tiap tingkat industri memerlukan dan membutuhkan pengetahuan tentang berbagai macam karakteristik bisnis busana. Dari karakteristik usaha busana tersebut, orang dapat memetakan kemampuan yang dimilikinya, minat dan bakat yang ada, serta mengetahui persaingan yang ada dalam dunia bisnis busana ini. Melalui berbagai mata kuliah yang terkait dengan manajemen, mahasiswa dapat memiliki berbagai pengetahuan tentang menganalisis potensi yang dimiliki, peluang usaha, menyusun strategi yang sesuai dengan tujuan dilaksanakannya usaha modiste.

Kelompok Bidang Keahlian (KBK) dosen yang ada pada Program studi antara lain adalah KBK kewirausahaan dan manajemen usaha busana. KBK merupakan kelompok dosen yang dibuat berdasarkan keahlian dosen, 
sangat menunjang dalam pengembangan keahlian melalui diskusi dalam membahas berbagai permasalahan khususnya dalam pelaksanaan tri dharma.

Berdasarkan temuan di lapangan, maka pembelajaran MUB Modiste terlaksana karena telah memiliki landasan yuridis berupa kurikulum, sesuai dengan visi misi program studi, pofil lulusan, learning outcome, renstrabis jurusan maupun program studi.Kelayakan program studi dalam penyelenggaraan pembelajaran MUB Modiste didukung oleh status prodi yang telah terakreditasi, dimilikinya sarana dan prasarana yang memadai, serta KBK dosen.

\section{Input (Masukan)}

Aspek input atau masukan pada pembelajaran MUB Modiste meliputi teknis pengelolaan, administrasi,alokasi waktu, dan sarana dan prasarana. Data tentang hal tersebut diambil melalui analisis dokumentasi dari arsip yang ada pada program studi.

Pengelolaan perkuliahan MUB Modiste diperoleh hasil bahwa MUB modiste disajikan pada semester 6 dan semester 7. Pada mahasiswa sampai dengan angkatan 2011, MUB Modiste disajikan dan diprogram mahasiswa pada semester 7. Mulai angkatan 2012 sampai dengan angkatan 2014, MUB Modiste disajikan dan diprogram pada semester 6. Berdasarkan informasi dari pengelola, dalam hal ini koorprodi Tata

\section{SIMPULAN}

PembelajaranMUB Modiste terlaksana karena telah memiliki landasan yuridis sebagai landasan pengembangan program. Latar belakang (context) pelaksanaan MUB Modiste di program studi tata busana Jurusan TI FT UM telah dirumuskan dan dilandasi denganlandasan filosofis berupa kebijakan yang memiliki nilai substansial menyiapkan mahasiswa untuk siap bekerja dengan penekanan pada penguasaan kompetensi yang dibutuhkan berupa kurikulum, sesuai dengan visi misi program studi, pofil lulusan, learning outcome, renstrabis jurusan maupun program studi. Kelayakan program studi dalam penyelenggaraan pembelajaran MUB Modiste didukung oleh status prodi yang telah terakreditasi, dimilikinya sarana dan prasarana yang memadai, serta KBK dosen.

Berdasarkan pada hasil temuan untuk aspek masukan (input), maka dapat dikatakan bahwa pembelajaran MUB Modiste didukung oleh aspek teknis pelaksanaan yang sudah rinci dan konsisten, alokasi waktu pelaksanaan yang memadai untuk pelaksanaan pembelajaran usaha, administrasi yang standar sesuai yang berlaku di Universitas, serta sarana prasarana yang memadai.

Pada aspek proses pelaksanaan pembelajaran MUB Modiste telah didukung oleh kompetensi dosen yang sesuai dan memadai, serta dalam prosesnya memiliki model yang sesuai dengan standar dan tujuan pembelajaran.

Upaya penyempurnaan pelaksanaan program MUB Modister dapat dilakukan Jurusan dan Prodi Tata Busana dengan memperhatikan indikator-indikator yang belum efektif dalam temuan penelitian ini, dengan cara: (1) memaksimalkan keterlibatan mahasiswa dalam penentuan target dan model pembelajaran hingga evaluasi, (2) melakukan revisi tujuan dan pedoman pelaksanaan MUB Modiste, (3) menjalin kerjasama dengan Industri yang ada untuk meningkatkan kelancaran kegiatan usahaagar tetap stabil, (3) memperhatikan dan mengelompokan mahasiswa berdasarkan kemampuannya agar setiap mahasiswa dapat berperan aktif dalam kegiatan pengelolaan usaha, (4) Dosen pembimbing hendaknya mengoptimalkan pembimbingan, intensitas dan kualitasnya, memberikan motivasi agar mahasiswa dapat memanfaatkan pembelajaran MUB Modiste sebagai sarana belajar yang harus dimaksimalkan, dan memberikan penilaian secara obyektif terhadap kinerja mahasiswa. 


\section{REFERENSI}

[1] Undang-Undang Republik Indonesia Nomor 20 Tahun 2003tentang Sistem Pendidikan Nasional.

[2] Direktorat Pembinaan Sekolah Menengah Kejuruan. 2015. Petunjuk Teknis Bantuan Soaial Pengembangan Teaching factory. Jakarta: Direktorat Jenderal Manajemen Pendidikan Dasar dan Menengah Departemen Pendidikan Nasional.

[3] Gall, Meredith D., Walter R. Borg dan Joyce P. Gall, 1996. Educational Research An Introduction, Sixth Edition. Longman Publishers.New York.

[4] Madaus, George F. , Michael S. Scriven, dan Daniel L. Stufflebeam,1985. Evaluation Models, Viewpoints on Educational and HumanService Evaluation. Kluwer-Nijhoff Publishing. Boston.

[5] Nulhakim, T. R. 2008. Evaluasi Program Akselerasi. Disertasi, Program Pascasarjana Universitas Negeri Jakarta. Jakarta.

[6] Perdhanawati, Vindhy. 2017. Manajemen Usaha Busana Konveksi, Modiste Dan Bordir Di Kecamatan Mayangan Kota Probolinggo. Jurnal Penelitian Busana dan Desain Vol. 1, No. 1, September 2017. Hal 11-24.

[7] Pophan, James W.. 1987.Educational Evaluation. Prentice Hall Inc. NewJersey.

[8] Sintawati, E. 2016. Pelaksanaan Teaching Factory Melalui Pembelajaran Manajemen Usaha Modiste Pada Program Studi Tata Busana. Makalah prosiding diseminarkan pada seminar Nasional Aptekindo. Medan.

[9] Sintawati, E, Nurdiansyah, R, Purwaningsih, N.E. 2017. Evaluasi Model Pembelajaran TF-6M Pada Perkuliahan MUB Modiste Prodi Tata Busana Jurusan Teknologi Industri FT UM. Malang: Laporan Penelitian tidak dipublikasikan.

[10] Sofan, A. Pengembangan dan Model Pembelajaran dalamKurikulum 2013. Prestasi Pustakaraya. Jakarta.

[11] Sudirta, IGK. 2006. Partisipasi Dunia Usaha dan Dunia Industri Dalam Pendidikan Kejuruan: Studi pada Pelaksanaan PI Siswa SMK Negeri Provinsi Bali Bidang Keahlian Tata Busana. Jurnal Pendidikan dan Pengajaran IKIP Negeri Singaraja, No. 2 TH. XXXIX April 2006 (www.undikshaac.id/images/img_item/491.doc).

Diakses 10 oktober 2011.

[12] Sunu, A. I.G.K. 2010. Pengelolaan Pendidikan Multikultural (Studi Kasus Pada SMP/MTs di Provinsi Bali). Disertasi tidak diterbitkan. Bandung: PPs UPI.

[13] Stufflebeam, Daniel L. dan Anthony J, Shinkfield. 1986. SystematicEvaluation, A Self-Instructional Guide to Theory and Practice,Kluwer-Nijhoff Publishing. Boston.

[14] Wening, S dan Savitri, S. 1994. Dasar Pengelolaan Usaha Busana. Yogyakarata: FPTK IKIP Yogyakarta.

[15] Yerusalem, M.A. 2011. Manajemen Usaha Busana. Yogyakarta: Universitas Negeri Yogyakarta 